\title{
Analisis Efisiensi Saluran Pemasaran Jambu Mete di Desa Rakadua, Kecamatan Poleang Barat, Bombana
}

Nurfadila ${ }^{1}$, Campina Illa Prihantini ${ }^{*}$, Erni ${ }^{1}$, Samaria $^{1}$, Erwin ${ }^{1}$

${ }^{1}$ Program Studi Agribisnis, Fakultas Pertanian, Perikanan Dan Peternakan, Universitas Sembilanbelas November Kolaka. "Corresponding author: campinailla26@gmail.com

\section{Article Info}

\section{Article history:}

Received 06 July 2021

Received in revised from 26 July 2021

Accepted 26 September 2021

DOI: https://doi.org/10.32938/ag.v6i3.1406

Keywords:

Channels

Marketing

Cashew

\begin{abstract}
Abstrak
The main problem in this study is that the cashews sold by farmers are still in the form of logs and not in processed form (processed cashew kernels). The purpose of this study was to analyze the trading system and marketing margins of cashew in Rakadua Village, Bombana Regency. The research method used in this study is a qualitative research with a descriptive approach which aims to provide an overview of the research problem. Based on the results of the study, the trade system used by cashew farmers in Rakadua Village, Poleang Barat District, Bombana Regency has used these four trading channels. Marketing channel I is the simplest trading system pattern, while marketing channel II, III, and IV are the most complex channels, namely by passing the most intermediaries. The results of this study may become the basis in the process of formulating policies issued by the government in order to improve the quality of cashews, especially for farmers.
\end{abstract}

\section{Pendahuluan}

Tanaman jambu mete (Anacardium occidentale L.) merupakan salah satu tanaman perkebunan yang memiliki arti ekonomi yang cukup besar sebagai bahan baku agroindustri. Selain buah dan bijinya, akar, daun dan batang sangat bermanfaat sebagai obat tradisional, bahan anti rayap dan pengawet. Sentra budidaya dan pengembangan jambu mete terbesar yaitu di Sulawesi Tenggara, Nusa Tenggara Timur (NTT), Sulawesi Selatan, Jawa Timur, Nusa Tenggara Barat (NTB) dan Jawa Tengah (Listyati \& Sudjarmoko, 2011). Luas areal jambu mete di Sulawesi Tenggara sebesar 119.237 ha dengan produksi 28.498 ton (Direktorat Jenderal Perkebunan, 2015).

Selain itu, usaha perkebunan jambu mete menjadi sumber pendapatan petani, penghasil bahan baku industri makanan, penciptaan lapangan kerja dan pengembangan wilayah. Indonesia sudah memulai industri perkebunan dan pengolahan jambu mete dari tahun 1975 dengan luas lahan awal 58.000 ha, dan hingga saat ini jambu mete masih merupakan komoditas unggul nasional karena hasil gelondongnya bernilai ekonomi (Zahir \& Sanawir, 2018). Sepanjang tahun 1990-an Indonesia merupakan negara penghasil mete penting di Asia yang menempati urutan produsen utama jambu mete. Indonesia mampu mengekspor sekitar 50\% dari produksi mete mentah (ITPC, 2015). Saat ini luas lahan perkebunan jambu mete yang dimiliki oleh Indonesia yaitu 510.113 ha (Ditjenbun, 2019).

Produksi tanaman jambu mete Indonesia tahun 2017 mencapai 135.569 ton dari luasan area 506.752 ha (Ditjenbun, 2018). Pada tahun berikutnya, diperkirakan kebutuhan akan mete terus meningkat, sejalan dengan meningkatnya jumlah penduduk, maka perlu dukungan pemerintah dalam pengembangan tanaman jambu mete. Pengembangan tanaman jambu mete di Indonesia masih tergolong rendah dari segi produktivitasnya. Secara nasional, produktivitas rata-rata hanya $432 \mathrm{~kg} / \mathrm{ha}$. Sedangkan negara lain, seperti Vietnam, produktivitasnya $3894 \mathrm{~kg} /$ ha dari luas areal 305.791 ha dan produksi 1.190.900 ton. Indonesia mengisi 117.400 ton (FAO, 2015).

Usahatani dalam arti luas memiliki dua permasalahan utama, yakni pemasaran dan pembiayaan (Sukesi ,2011 dan Prihantini , 2015). Pun demikian pada usaha perkebunan jambu mete. Dalam hal pemasaran, mete yang dijual petani masih dalam bentuk gelondongan dan bukan dalam bentuk olahan (biji mete olahan, cashews kernels). Biasanya para petani menjual kepada pedagang pengumpul langganannya. Hal ini tentu mempengaruhi nilai jual dari mete itu sendiri. Keberadaan pedagang pengumpul juga tentu berpengaruh terhadap tingkat efisiensi saluran pemasaran yang dilalui. Semakin panjang suatu saluran maka semakin inefisien saluran tersebut. Hal ini dikarenakan mengurangi nilai farmer's share yang akan diterima oleh petani. Tujuan penelitian ini adalah untuk menganalisis tataniaga dan margin pemasaran jambu mete di Desa Rakadua, Kecamatan Poleang Barat, Kabupaten Bombana.

\section{Metode Penelitian Jenis Penelitian}

Jenis penelitian ini menggunakan jenis penelitian deskriptif dengan pendekatan kualitatif dengan memberikan gambaran seluruh permasalahan tentang analisis tataniaga dan margin 
pemasaran jambu mete di Desa Rakadua, Kecamatan Poleang Barat, Kabupaten Bombana. Dalam penelitian ini menggunakan Metode penelitian kualitatif (Sugiyono,2016) bahwa pendekatan metode kualitatif adalah motode penelitian yang berlandaskan pada paradigma fenomol digunakan untuk untuk meneliti pada kondisi objek yang alamiah, (sebagai lawannya adalah eksperimen) dimana peneliti adalah sebagai instrument kunci, teknik pengumpulan data dilakukan secara triangulasi (gabungan), analisis data bersifat induktif/kualitatif.

\section{Lokasi dan Waktu Penelitian}

Penelitian ini dilakukan di Desa Rakadua, Kecamatan Poleang Barat, Kabupaten Bombana. pemilihan lokasi ini karena mete yang dijual oleh petani masih dalam bentuk gelondongan dan bukan dalam bentuk olahan (biji mete olahan, cashews kernels). Penelitian ini dilakukan mulai tanggal 5 April sampai 22 Juli 2021

\section{Metode Pengambilan Sampel}

Pengambilan responden lembaga tataniaga di Desa Rakadua, Kecamatan Poleang Barat, Kabupaten Bombana ini dilakukan dengan metode bola salju (snowball) yaitu 5 orang pedagang pengumpul desa, 2 orang pedagang pengumpul besar dan 8 orang pedagang pengecer yang saling terkait dalam rantai tataniaga. Selain itu dilakukan pengamatan langsung terhadap kegiatan tataniaga dan penelusuran saluran tataniaga atau lembaga-lembaga tataniaga dari mulai petani, pedagang pengumpul,sampai dengan pedagang pengecer dan konsumen akhir.

\section{Metode Analisis Data}

Metode analisis yang digunakan yaitu analisis deskriptif. Analisis berdasarkan data primer yang bersumber dari responden petani dan responden pedagang yang dilengkapi oleh data kualitatif yang berasal dari perhitungan marjin tataniaga. Pola saluran tataniaga di identifikasi dengan mengategorikan setiap saluran tataniaga yang muncul. Berdasarkan pola saluran tataniaga dihitung nilai marjin tataniaga. Nilai marjin pemasaran secara matematis dapat dihitung dengan:

$\mathrm{MP}=\mathrm{Pr}-\mathrm{Pf}$

Dimana :

MP = Marjin Pemasaran (Rupiah)

$\operatorname{Pr}=$ Harga Jambu Mete ditingkat Pengepul (Rp/Ton)

Pf = Harga Jambu Mete ditingkat Petani (Rp/Ton)

\section{Hasil dan Pembahasan}

\section{Analisis Saluran Pemasaran}

Tahapan saluran tataniaga yang digunakan oleh petani jambu mete di Desa Rakadua, Kecamatan Poleang Barat, Kabupaten Bombana. Saluran tataniaga untuk Jambu Mete menggunakan empat saluran tataniaga tersebut. Saluran pemasaran I merupakan pola tataniaga yang paling sederhana, sedangkan saluran pemasaran II, III, dan IV merupakan salurang yang paling kompleks yaitu dengan melewati perantara paling banyak. Panjang pendeknya saluran tataniaga tergantung pada jarak antara produsen dan konsumen (Prihantini dan Lutfiyanto, 2019). Semakin jauh jarak antara produsen dan konsumen, maka makin panjang saluran tataniaga yang terjadi (Hanafiah dan Saefuddin, 2004; Prihantini ,2015). Rantai distribusi menurut Taylor (2000) merupakan kegiatan yang kompleks dan membutuhkan berbagai fasilitas dan aktivitas termasuk di dalamnya produksi dan penyaluran produk, dari produsen ke konsumen akhir. Hal ini dapat dilihat pada Gambar 1 berikut.

\section{Saluran Pemasaran I}

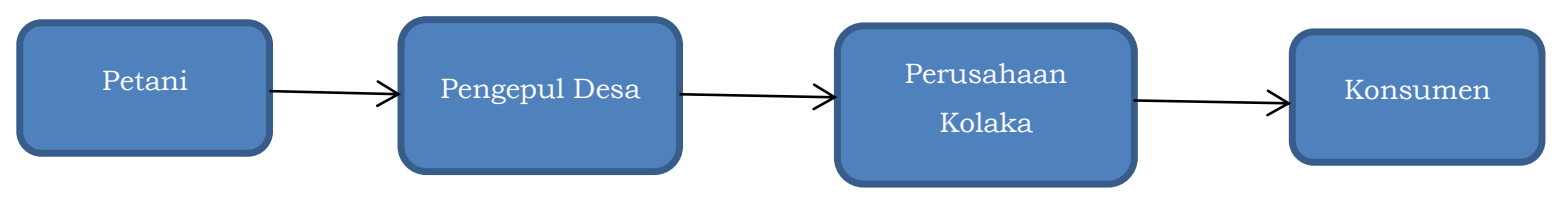

\section{Saluran Pemasaran II}

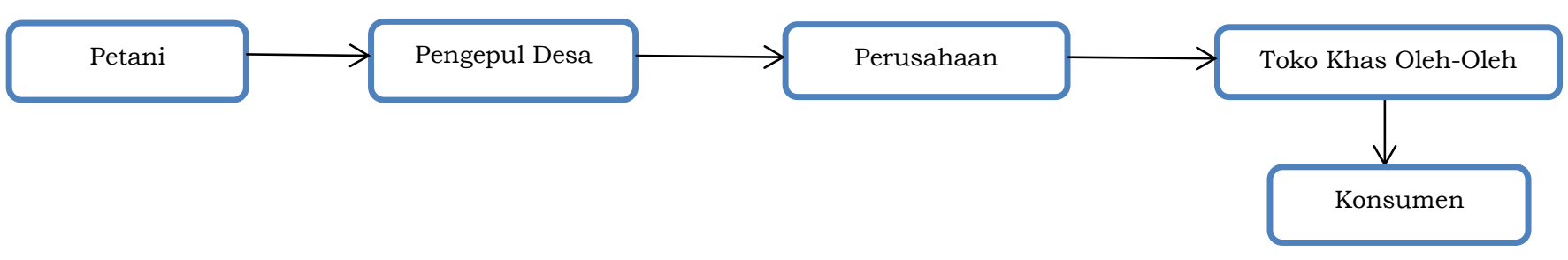




\section{Saluran Pemasaran III}

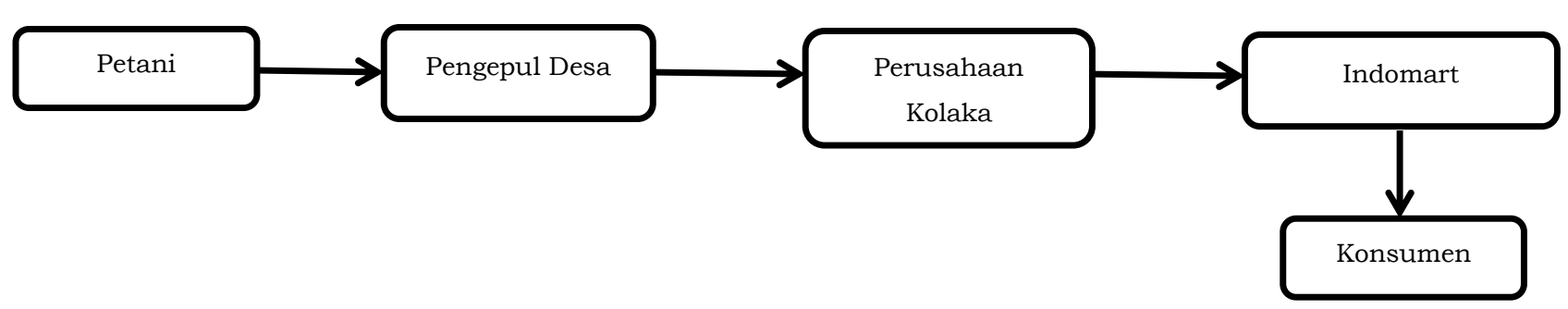

\section{Saluran Pemasaran IV}

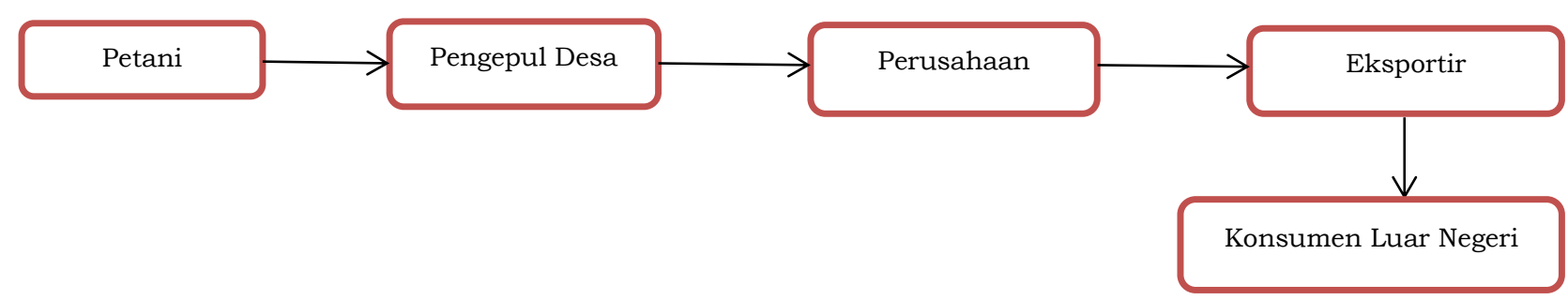

Gambar 1. Saluran Pemasaran Jabu Mete Di Desa Rakadua, Poleang Barat, Bombana; Sumber: Data Primer Diolah, 2021

\section{Analisis Fungsi Lembaga Pemasaran}

Fungsi-fungsi pemasaran ini menggunakan analisis kualitatif dimana dengan mengukur setiap lembaga pemasaran yang terdapat di lapangan, melalui pengukuran tiga aspek fungsi-fungsi pemasaran yang dilakukan pada setiap lembaga pemasaran yaitu fungsi pertukaran, fungsi fisik dan fungsi fasilitas. Hasil penenlitian menunjukkan setiap lembaga pemasaran melakukan fungsifungsi pemasaran yang berbeda dengan tujuan untuk memperluas penjualan Jambu Mete. Fungsi pemasaran merupakan aktivitas penting yang dispesialiasi dan dijalankan pada proses pemasaran (Hutauruk, 2003). Analisis ini dilakukan dengan mendeskripsikan setiap lembaga-lembaga pemasaran terhadap fungsi-fungsi pemasaran yang dilakukan. Hasil analisis fungsi pemasaran tertera pada Tabel 1. Hasil Penelitian yang kami lakukan menunjukkan bahwa seluruh fungsifungsi pemasaran dilakukan semua oleh pedagang pengumpul tingkat desa, hal ini dikarenakan pedagang pengumpul desa menjual produk dengan volume yang relatif tinggi sehingga perlakuan untuk memasarkan produknya semakin banyak.

Tabel 1. Fungsi Lembaga Pemasaran Jambu Mete 2021, Desa Rakadua,Kecamatan Poleang Barat, Kabupaten Bombana

\begin{tabular}{|c|c|c|c|c|c|c|c|c|c|}
\hline \multicolumn{10}{|c|}{ Fungsi Pemasaran } \\
\hline \multirow{2}{*}{ Saluran Tataniaga } & \multicolumn{3}{|c|}{ Pertukaran } & \multicolumn{3}{|c|}{ Fisik } & \multicolumn{3}{|c|}{ Fasilitas } \\
\hline & Jual & Beli & Kemas & Angkut & Simpan & Sortir & Resiko & Biaya & Informasi Pasar \\
\hline \multicolumn{10}{|l|}{ Saluran I } \\
\hline Petani & + & - & + & + & + & + & - & - & + \\
\hline Pengepul Desa & + & + & + & + & + & + & + & + & + \\
\hline Perusahaan Kolaka & + & + & + & + & + & + & + & + & + \\
\hline Konsumen & - & + & - & - & - & - & * & - & - \\
\hline \multicolumn{10}{|l|}{ Saluran II } \\
\hline Petani & + & - & + & + & + & + & - & - & + \\
\hline Pengepul Desa & + & + & + & + & + & + & + & + & + \\
\hline Perusahaan Kolaka & + & + & + & + & + & + & + & + & + \\
\hline Toko Khas Oleh-Oleh & + & + & * & - & + & - & + & + & + \\
\hline \begin{tabular}{|c|} 
Konsumen \\
\end{tabular} & - & + & - & - & - & - & * & - & - \\
\hline \multicolumn{10}{|l|}{ Saluran III } \\
\hline Petani & + & - & + & + & + & + & - & - & + \\
\hline Pengepul Desa & + & + & + & + & + & + & + & + & + \\
\hline Perusahaan Kolaka & + & + & + & + & + & + & + & + & + \\
\hline Indomaret & + & + & - & - & + & - & + & + & + \\
\hline Konsumen & - & + & - & - & - & - & * & - & - \\
\hline \multicolumn{10}{|l|}{ Saluran IV } \\
\hline Petani & + & - & + & + & + & + & - & - & + \\
\hline Pengepul Desa & + & + & + & + & + & + & + & + & + \\
\hline Perusahaan Kolaka & + & + & + & + & + & + & + & + & + \\
\hline Eksportir & + & + & * & + & + & - & + & + & + \\
\hline Konsumen LN & - & + & - & - & - & - & * & - & - \\
\hline
\end{tabular}

Sumber: Data Primer Diolah, 2021

Keterangan :

+ : Melakukan Fungsi Pemasaran 
- : Tidak Melakukan Fungsi Pemasaran

* : Kadang-Kadang Melakukan Fungsi Pemasaran

\section{Analisis Efisiensi Saluran Pemasaran \\ 1) Marjin Pemasaran Jambu mete}

Margin pemasaran adalah selisih harga dari dua tingkat rantai pemasaran atau selisih harga yang dibayarkan di tingkat pengecer (konsumen) dengan harga yang diterima oleh produsen. Dengan kata lain, margin pemasaran merupakan perbedaan harga ditingkat konsumen (harga yang terjadi karena perpotongan kurva permintaan primer dengan kurva penawaran turunan) dengan harga di tingkat produsen (harga yang terjadi karena perpotongan kurva penawaran primer dengan permintaan turunan) (Hastuti dan Rahim, 2007).

Marjin pemasaran yaitu selisih harga jual dengan harga beli dan merupakan salah satu indikator yang digunakan untuk mengukur tingkat efisiensi suatu sistem pemasaran. Marjin pemasaran terdiri dari biaya pemasaran dan keuntungan lembaga pemasaran. Dalam pembahasan ini akan diuraikan marjin pemasaran melalui dari tingkat pedagang pengumpul desa sampai ke pedagang besar pada masing-masing saluran pemasaran (Rosmawati, H, 2011).

Marjin pemasaran merupakan perbedaan harga di tingkat petani atau produsen dengan harga di tingkat konsumen akhir atau tingkat lembaga tataniaga akhir. Analisis marjin tataniaga dapat dilihat pada grafik saluran pemasaran I. Berdasarkan hasil analisis tataniaga atau saluran pemasaran jambu mete yang ada di Desa Rakadua, Kecamatan Poleang Barat, Kabupaten Bombana. Untuk mengetahui saluran pemasaran yang efisiensi dengan menggunakan marjin pemasaran yang mengatakan bahwa saluran pemasaran I adalah saluran pemasaran jambu mete yang paling efisien. Hal ini sesuai dengan pendapat Hanafie (2010) yang menyatakan bahwa marjin tataniaga dilakukan untuk mengetahui saluran tataniaga yang paling efisien diantara saluran yang lain. Hasil analisis saluran pemasaran II, III, dan IV memiliki kesamaan yaitu melibatkan 5 lembaga pemasaran.

\section{2) Harga Masing-masing Lembaga Pemasaran}

Berdasarkan hasil penelitian harga gelondongan mete terbentuk atas kesepakatan antara petani dengan pengumpul, bukan atas besarnya jumlah permintaan dan penawaran di pasar. Hal ini terjadi karena produk mete gelondong bukanlah produk yang siap dikonsumsi, namun masih memerlukan proses pengolahan / pengupasan, dan para petani belum mampu melakukannya, sehingga keterikatan kepada pedagang pengumpul sangat tinggi untuk dapat menyampaikan produk mete gelondong kepada perusahaan pengolah / pabrik yang selanjutnya sampai kepada konsumen akhir.

Adapun harga jambu mete dari masing-masing lembaga tataniaga yang dimulai dari tingkat petani, pengepul desa, perusahaan Kolaka, toko khas oleh-oleh, Indomart, eksportir serta ke komsumen memiliki harga yang berbeda-beda. Hal ini dapat dilihat dari tingkat petani yang memberikan harga ke pengepul desa sebesar $\mathrm{Rp} 12.000 / \mathrm{Kg}$, dari tingkat pengepul desa ke perusahaan kolaka dengan harga Rp $17.000 / \mathrm{kg}$, dari lembaga perusahaan kolaka ke konsumen seharga $\mathrm{Rp} 85.000 / \mathrm{kg}$ (Saluran pemasaran I). dari tingkat petani yang memberikan harga ke pengepul desa sebesar Rp $12.000 / \mathrm{Kg}$, dari tingkat pengepul desa ke perusahaan kolaka dengan harga Rp $17.000 / \mathrm{kg}$, dari lembaga perusahaan kolaka ke toko khas oleh-oleh seharga Rp.85.000/kg, kemudian dari toko khas oleh-oleh ke konsumen seharga Rp 120.000/kg (Saluran pemasaran II). dari tingkat petani yang memberikan harga ke pengepul desa sebesar Rp 12.000/Kg, dari tingkat pengepul desa ke perusahaan kolaka dengan harga Rp 17.000/kg, dari lembaga perusahaan kolaka ke Indomart seharga $\mathrm{Rp} 85.000 / \mathrm{kg}$, kemudian dari Indomart konsumen seharga Rp 130.000/kg (Saluran pemasaran III). dari tingkat petani yang memberikan harga ke pengepul desa sebesar Rp $12.000 / \mathrm{Kg}$, dari tingkat pengepul desa ke perusahaan kolaka dengan harga Rp 17.000/kg, dari lembaga perusahaan kolaka ke Eksportir seharga Rp 95.000/kg, dari Eksportir ke konsumen luar negeri seharga Rp 150.000/kg (Saluran pemasaran IV).

\section{3) Komponen Biaya Pemasaran}

a. Biaya pengangkutan

Menurut (Azis dan Asrul, 2014) transportasi merupakan kebutuhan turunan atau kebutuhan kedua, dalam kegiatan ekonomi masyarakat. Dalam pembangunan wilayah secara menyeluruh, peranan transportasi telah memberikan dampak yang amat baik, khususnya pada hubungan antar kemudahan. Transportasi juga dijadikan salah satu variabel yang memiliki pengaruh terhadap roda perekonomian. Sebagai penunjang, pendorong, serta sebagai penggerak perekonomian yang merupakan beberapa fungsi dari transportasi (Haryono, 2010). Berdasarakan pengertian diatas bahwa pengangkutan merupakan pemindahan barang atau jasa yang dilakukan oleh orang lain dengan menggunakan transportasi umum atau pribadi. Dari hasil penelitian yang dilakukan di 
Desa Rakadua, Kecamatan Poleang Barat, Kabupaten Bombana bahwa hasil wawancara pengepul desa dalam pengangkutan jambu mete mereka telah menggunakan transportasi umum dengan biaya angkutan Rp 1.500.000.

Tabel 2. Marjin Pemasaran Jambu Mete Di Desa Rakadua,Kecamatan Poleang Barat,Kabupaten Bombana

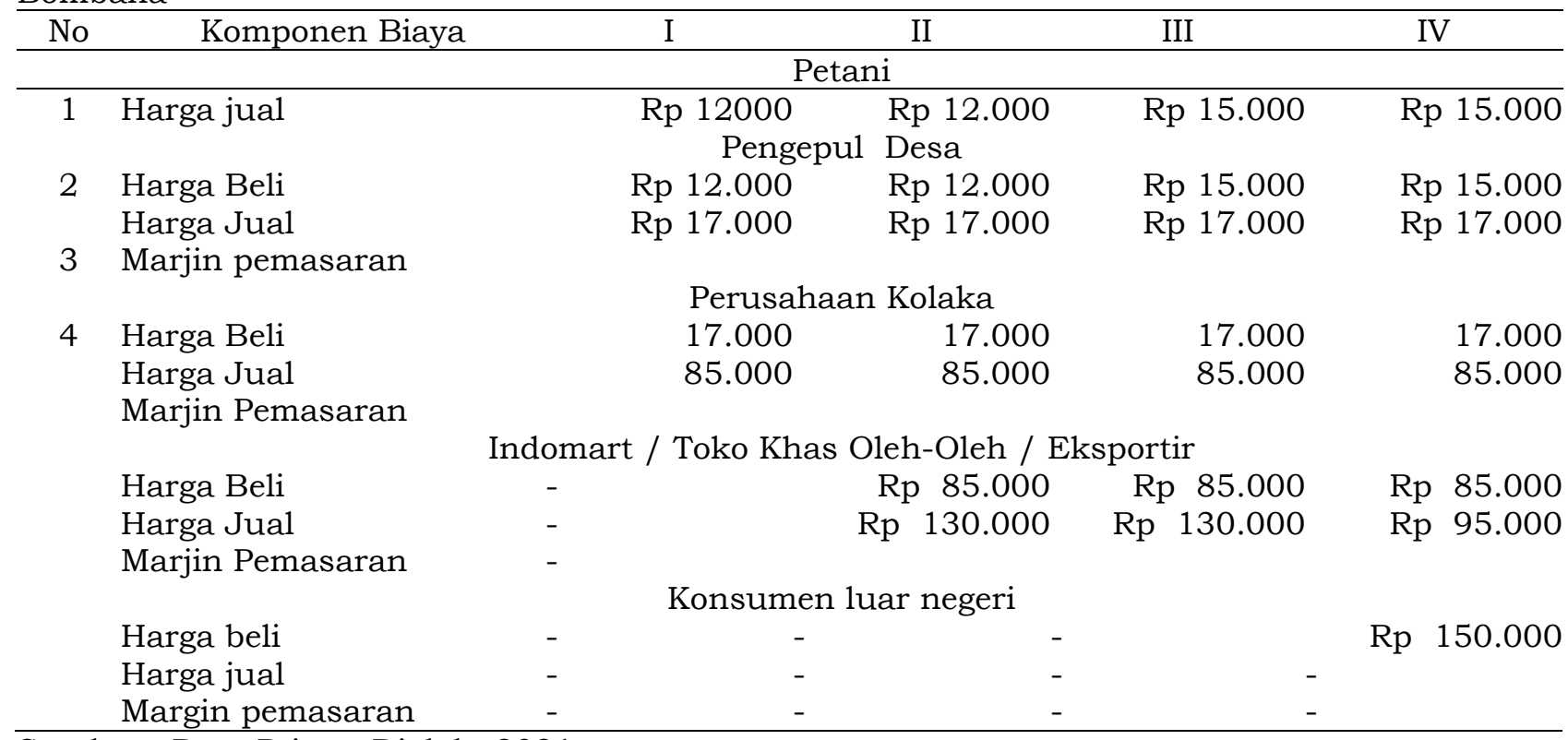

Sumber : Data Primer Diolah, 2021

\section{b. Biaya Tenaga Kerja}

Menurut Hamza (2014), tenaga kerja adalah tenaga yang bekerja di dalam maupun luar hubungan kerja dengan alat produksi utama dalam proses produksi baik fisik maupun pikiran. Dalam pekerjaan jambu mete yang dilakukan oleh pengepul desa dengan melibatkan pihak lain sebanyak 5 orang dengan biaya yang di berikan Rp 25.000 per orang.

c. Biaya Pengemasan

Menurut Rodriguez (2008) pengemasan adalah proses merubah kondisi dari bahan pangan dengan penambahan senyawa aktif sehingga mampu memperpanjang umur simpan dari bahan pangan yang dikemas dan juga meningkatkan keamanan serta mempertahankan kualitas. Pengemasan jambu mete yang ada di Desa Rakadua telah menggunakan karung dengan berat bobot $50 \mathrm{~kg}$ dengan harga Rp 500 perkarung, dengan pemilihan bahan dari karung dapat memperlambat pembusukan.

d. Biaya Retribusi

Menurut Marihot (2016) retribusi daerah adalah pungutan daerah sebagai pembayaran atas jasa atau pemberian izin tertentu yang khusus disediakan atau diberikan oleh pemerintah daerah untuk kepentingan pribadi atau badan. Hal ini biaya retribusi yang di bayarkkan oleh pengepul desa kepada retribusi daerah sebesar Rp 25.000 hal ini di sesuaikan dengan muatan yang dibawa oleh pengirim barang.

\section{4) Simpulan}

Berdasarkan hasil penelitian di atas dapat disimpulkan bahwa tahapan saluran tataniaga yang digunakan oleh petani jambu mete di Desa Rakadua, Kecamatan Poleang Barat, Kabupaten Bombana telah menggunakan empat saluran tataniaga tersebut. Saluran pemasaran I merupakan pola tataniaga yang paling sederhana, sedangkan saluran pemasaran II, III, dan IV merupakan saluran yang paling kompleks yaitu dengan melewati perantara paling banyak, serta harga jambu mete dari masing-masing lembaga berbeda-beda sedangkan komponen biaya jambu mete mereka telah menggunakan transportasi umum dengan biaya angkutan Rp 1.500 .000 dan dalam pengerjaan serta pengemasan telah menggunakan karung dengan berat bobot $50 \mathrm{~kg}$ dengan harga Rp 500 perkarung, dengan pemilihan bahan dari karung dapat memperlambat pembusukan.

\section{Saran}

Adapun saran dari kesimpulan di atas bahwa analisis tataniaga dan margin pemasaran telah dilakukan hingga konsumen terakhir. Sehingga melihat margin pemasaran secara keseluruhan serta dapat melihat biaya dalam pembiayaan tenaga kerja serta pembiayaan lainnya dan hasil 
analisis tataniaga jambu mete menjadi pedoman bagi pemerintah agar lebih banyak untuk menghasilkan suatu produk yang berbahan dasar jambu mete sehingga dapat di kemas dengan menggunakan kemasan yang lebih keren utuk menarik minat pelanggan.

\section{Pustaka}

Azis, R., \& Asrul. (2014). Pengantar Sistem dan Perencanaan Transportasi. Yogyakarta: Deepublish.

Direktorat Jendral Perkebunan. 2015. Pertumbuhan Areal Kelapa Sawit. www.ditjenbun .pertanian.go.id.

Ditjenbun (2019) Statistik Perkebunan Indonesia 2017-2019. Direktorat Jenderal Perkebunan, 41 $\mathrm{p}$.

FAO. 2015. http://faostat.fao.org/site/567/ DesktopDefault.aspx?PageID=567\#ancor diunduh tg1 29 September 2016.

Hamzah \& Nina. 2014. Teori Kinerja dan Pengukurannya. Jakarta: Rineka Cipta.

Hanafiah, M. Dan A Saefuddin. 2004. Tataniaga Hasil Perikanan. Universitas Press. Jakarta.

Hanafie, Mamduh. M (2010). Manajemen Keuangan. Edisi Pertama. Yogyakarta : BPFE

Hutauruk. J. 2003. Tataniaga Hasil Pertanian. UNIKA, Medan.

Hastuti dan Rahim, 2008. Ekonomi Produksi Pertanian. Swadaya. Bogor

Haryono, Sigit. 2010. Analisis Kualitas Pelayanan Angkutan Umum (Bus Kota) di Kota Yogyakata. Jurnal Transportasi. Vol 7 No 1 Juli 2010.

Listyati, D., \& Sudjarmoko, B. (2011). Nilai tambah ekonomi pengolahan jambu mete Indonesia. Journal of Industrial and Beverage Crops, 2(2), 132499.

Marihot P. 2016. Pajak Daerah dan Retribusi Daerah. Edisi Revisi. Jakarta: Rajawali Pers.

Nogoseno, 1996. Pengmbangan Jambu Mete Di Indonesia. Prosiding Forum Komunikasi Ilmiah Komoditas Jamu Mete. Bogor.

Prihantini, C. I. 2015. Efisiensi Pemasaran Garam Rakyat di Desa Padelegan, Kecamatan Pademawu, Kabupaten Pamekasan, Madura, Jawa Timur [Skripsi]. Bogor (ID): Institut Pertanian Bogor.

Prihantini, C.I. dan Lutfiyanto. 2019. Analisis Saluran Distribusi Sarana Produksi Pertanian (Saprotan) Pupuk di Kabupaten Pamekasan. Agrimor : Jurnal Agribisnis Lahan Kering. 4 (4) : 45-48.

Rodriguez D., Andrade. (2008). Ikon Budaya Konsumtif. Yogyakarta: Relief.

Rosmawati, H, 2011. Analisis Efisiensi Pemasaran Pisang Produksi Petani di Kecamatan Lengkiti Kabupaten Ogan Komering Ulu. Jurnal AgronobiS, Vol. 3, No. 5, Maret 2011 ISSN: 1979 $8245 \mathrm{X}$

Sugiyono, 2016, Metode Penelitian Administrasi Kebijakan Publik Konsep dan Perkembangan Imu Indonesia. Bandung Graha Ilmu.

Sukesi. 2011. Analisis Perilaku Masyarakat Petani Garam Terhadap Hasil Usaha di Kota Pasuruan. Pasuruan (ID): Jurnal Mitra Ekonomi dan Manajemen Bisnis.

Tjakranegara Soegijatna (1995), Hukum Pengangkutan Barang dan Penumpang, Rineka Cipta, .

Taylor Bernard W \& Russell Roberta. 2000. Operations Management. Third Edition. Prentice Hall. New York.

Zahir N. \& Sanawiri, B. (2018) Competitive advantage of Indonesian cashew nuts in international market. Jurnal Administrasi Bisnis (JAB). 54 (1), 66-73. 